\title{
Wireless sensor network for monitoring thermal evolution of the fluid traveling inside ground heat exchangers
}

\author{
Julio Martos, Álvaro Montero (*), José Torres and Jesús Soret \\ Universitat de València \\ ( $^{*}$ Universidad Politécnica de Valencia \\ Spain
}

\section{Introduction}

Ground-Coupled Heat Pump (GCHP) systems are an attractive choice of system for heating and cooling buildings (Genchi, 2002; Sanner, 2003; Omer, 2008; Urchueguía, 2008). By comparison with standard technologies, these heat pumps offer competitive levels of comfort, reduced noise levels, lower greenhouse gas emissions, and reasonable environmental safety. Furthermore, their electrical consumption and maintenance requirements are lower than those required by conventional systems and, consequently, they have a lower annual operating cost (Lund, 2000). Ground source systems are recognized by the U.S. Environmental Protection Agency as being among the most efficient and comfortable heating and cooling systems available today (US EPA, 2008). The European Community and other international agencies, such as the DOE or the American International Energy Agency, are considering GCHP in the field of "heat production from renewable sources". In 2002, the growth in the number of air conditioning systems driven by ground coupled (geothermal) heat pumps was estimated in the range from $10 \%$ to $30 \%$ each year (Bose 2002). The number of installed units worldwide, around 1.1 million (Spitler, 2005), illustrates the high acceptance of this emerging technology in the Heating, Ventilation \& Air Conditioning (HVAC) market.

A Ground Coupled Heat Pump is a heat pump that uses soil as source or sink of heat. A GCHP exchanges heat with the ground through a buried U-tube loop. Since this exchange strongly depends on the thermal properties of the ground, it is very important to have knowledge of these properties when designing GCHP air-conditioning systems. The length of Borehole Heat Exchangers (BHE) needed for a given output power greatly depends on soil characteristics, such as temperature, particle size and shape, moisture content, and heat transfer coefficients. Correct sizing of the BHEs is a cause for design concern. Key points are building load, borehole spacing, borehole fill material, and site characterization. Over-sizing carries a much higher penalty than in conventional applications. Methods to estimate ground properties include literature searches, conducting laboratory experiments on soil/rock samples and/or performing field tests. Due to these factors, the completion of a 
thermal response test (TRT), which determines the thermal parameters of the underground, is very important.

The standard TRT consists in injecting or extracting a constant heat load inside the BHE and measuring changes in temperature of the circulating fluid. The outputs of the thermal response test are the inlet and outlet temperature of the heat-carrier fluid as a function of time. From these experimental data, and with an appropriate model describing the heat transfer between the fluid and the ground, the thermal conductivity of the surroundings is inferred. A delicate aspect of the measuring process is to maintain constant the heat injection or extraction because a $5 \%$ of power fluctuation can lead to errors of around $40 \%$ for thermal conductivity (Witte 2002).

Thermal response tests with mobile measurement devices were first introduced in Sweden and the USA in 1995 (Eklöf and Gehlin, 1996; Austin, 1998). Since then, the method has been further developed, and its use has spread to several other countries. Kelvin's infinite linesource model is commonly used for evaluation of response test data because of its simplicity and speed (Mogensen, 1983; Eskilson, 1987; Hellström, 1991). This model is dominant in Europe, while the use of the cylindrical-source model (Carslaw and Jaeger, 1959) with parameter-estimating techniques is common in North America (Austin, 1998; Beier, 2008).

Other works have explored alternative methods to perform TRT and obtain ground thermal properties. There is a procedure based on fiber optic thermometers (Hurtig 2000) to determine the dynamic behavior of the heat exchanging medium inside a borehole heat exchanger. Another procedure attempts to determine the ground conductivity based on prior knowledge of the local geothermal flow (Rohner 2005). The importance of having TRT techniques is illustrated by the initiative of the Energy Conservation through Energy Storage (ECES), a Implementing Agreement (IA) of the International Energy Agency (IEA), to launch in 2006 the Annex 21, Thermal Response Test (Nordell 2006).

Most of the models for analyzing data from thermal response tests are constrained by the fact that only two measures are available, the inlet and outlet temperature of the heat-carrier fluid as a function of time. Thus, the analysis procedure arrives at the question of what is the right comparison between these two measures of fluid temperatures and the ground modelled temperatures that depend on spatial coordinates. Different aproaches are followed in the literature, such as comparing the average fluid temperature with the ground temperature at the mid-depth of the borehole heat exchanger, or comparing it with the average ground temperature in the neigbourghood of the heat exchangers. To avoid this ambiguity, it is desirable to know the evolution of the fluid temperature along its way through the U- pipe. Then, it will be possible to compare the fluid temperature at a spatial position with the corresponding ground modelled temperature at the correponding spatial point. The purpose of the instrument presented here is to measure the fluid temperature evolution and to improve the procedure to estimate thermal properties of ground heat exchangers.

Inspired by the implementations of wireless sensor networks, we have designed a new instrument to measure the temperature of the heat transfer fluid along the borehole exchanger by autonomous wireless sensor. The instrument consists of a device that inserts and extracts miniaturized wireless sensors in the borehole with a mechanical subsystem that is composed of a circulating pump and two valves. This device transmits the acquisition configuration to the sensors, and downloads the temperature data measured by the sensor along its way through the borehole heat exchanger. Each sensor is included in a sphere of 25 
$\mathrm{mm}$ in diameter and contains a transceiver, a microcontroller, a temperature sensor, and a power supply. This instrument allows the collection of information about the thermal characteristics of the geological structure of soil and its influence on borehole thermal behavior in dynamic regime, and it facilitates an easier and more reliable implementation of the thermal response test.

This chapter is organized as follows. Section 2 discuses the relevance of monitoring the fluid temperature evolution along the BHE. Sections 3, 4 and 5 present the considerations adopted for design, firmware, and time synchronization, respectively. Section 6 presents other implementations, and section 7 presents energy harvesting considerations. Finally, section 8 presents the conclusions of this work.

\section{Monitoring relevance in $\mathrm{BHE}$}

The knowledge of the heat transfer properties of a ground heat exchanger is the key to calculating the number and depth of wells needed in a plant; these parameters have a strong dependence on the local characteristics of soil. The conventional TRT makes an approach to the knowledge of the thermal characteristics of the environment surrounding the heat exchanger based on two parameters: the soil effective thermal conductivity and the borehole thermal resistance. Nevertheless, it cannot measure other important factors such as the effects of geological structure, humidity, and water currents. These aspects can be observed during drilling, but they cannot be quantified with a weighting factor by the conventional TRT. Furthermore, new TRT developments are trying to indirectly measure the effects of these factors by performing tests at different injected or extracted powers, and explaining the differences between the values obtained for each injected or extracted power as coming from geological structure, humidity, and water currents. This approach to obtain this information is constrained by the fact that only the inlet and outlet temperature of the heatcarrier fluid are available.

If all these effects and circumstances can be directly quantified, the design methodology could be modified to establish, in the implementation phase of drilling, the optimal balance between depth and number of drilling holes to maximize heat transfer and minimize the total drilling cost. This may be one of the key points in the expansion of the HVAC systems based on GCHP, especially in countries with moderate climates. For these reasons, the developed instrument, which is aimed at directly measuring the evolution of the temperature of the thermal fluid flowing inside a ground heat exchanger, attempts to monitor the heat exchange that occurs between the thermal fluid and the ground as a function of space and time.

\section{Design considerations}

The difficulty of this goal lies in the placement of temperature sensors at the desired points, without increasing the costs of installation or affecting the operation of the exchanger. In addition, the measure of temperatures is only necessary during the final stage of implementation, when the ground coupled heat exchanger is just being built, and is not necessary during operation time.

Other authors have proposed alternative systems to obtain the thermal evolution of the GCHE, from the standard TRT based on the Kelvin's theory of infinite line source, which 
has the advantage that only requires two measurements of temperature, to fiber-optic thermometers, requiring laser interferometer equipment.

The developed instrument is based on nodes of wireless sensor networks (Martos 2008), which are adapted to the functions and working conditions that occur in the BHE used in HVAC equipment with GCHP.

\subsection{Working principle}

The way to make the most accurate measure is to take the temperature of the same volume of thermal fluid at successive points, thus not masking the dynamics of the system in times of sudden changes in temperature. The working principle used by the instrument, which is shown in Figure 1. The measure of the temperature of the fluid along the tube exchanger, is performed by autonomous wireless sensors, which are carried by the thermal fluid. These probes are smaller than the diameter of the pipe and contain all the electronics needed to complete a set of measures along the pipeline and to download them to a central node.

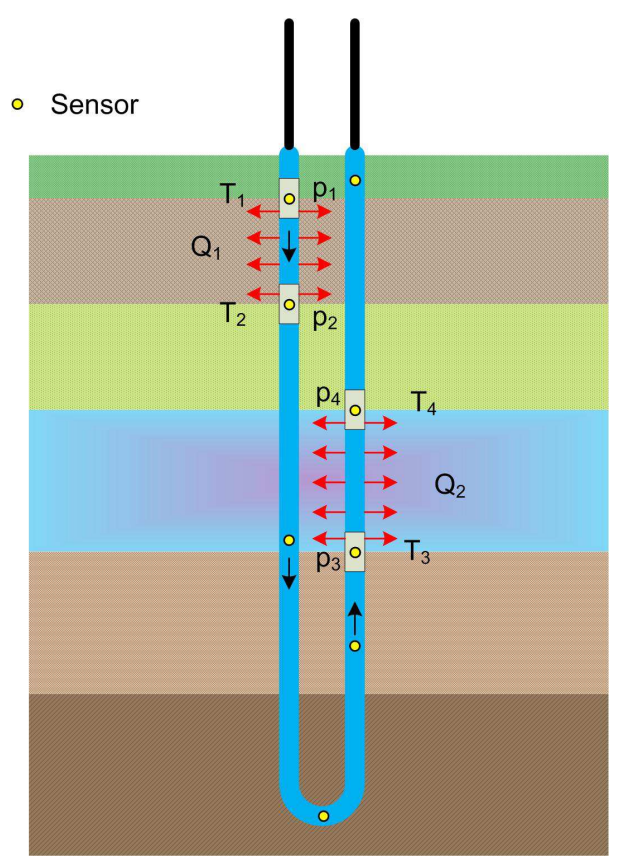

Fig. 1. Working principle of the instrument

The heat transferred $(\mathrm{Q})$ between the thermal fluid and soil between two points $\mathrm{p} 1$ and $\mathrm{p} 2$, can be calculated using the expression:

$$
Q=(T 2-T 1) * C_{p} * S *(p 2-p 1) * \rho
$$


Where T1 and T2 is the temperature of the fluid at points $\mathrm{p} 1$ and $\mathrm{p} 2$, respectively, Cp is the specific heat of the thermal fluid, $\mathrm{S}$ is the section of the tube exchanger, $\mathrm{p} 2-\mathrm{p} 1$ is the distance between the points of measurement, and $\mathrm{r}$ is the fluid density.

The probes of the instrument developed should be able to simultaneously obtain three magnitudes (position, temperature and time) to perform the desired analysis. Time is easy to measure because any system based on microprocessors incorporates clock circuitry. To measure the temperature, the probe must incorporate a conditioning circuit that meets the constraints of volume and consumption. To determine the position, there are two possible options: direct or indirect measurement. Direct measurement could be carried out by inclusion of a pressure sensor that measures the pressure changes while the probe is traveling along the pipe. Indirect measurement could be carried out by correlating the distance with another parameter. The first method requires additional circuitry, which negatively affects consumption and miniaturization. We have chosen the second method, calculating the position based on the time between successive samplings of the temperature and the speed of thermal fluid. Among other advantages, this method offers the following: minimizes the necessary circuitry, it reduces consumption, it can be used in heat exchangers that are buried in vertical or horizontal configuration.

The relationship between the distance (l) and the time between samples (if the probe is carried without sliding) is:

$$
1=F^{*} t_{s} / S
$$

Where, $\mathrm{F}$ is the flow of thermal fluid, ts is the time between two consecutive samples, and $\mathrm{S}$ is the section of pipe. If the density of the sphere that constitutes the probe is close to the density of the thermal fluid, it will be carried both vertical configurations and horizontal configurations. To verify this, we have completed a set of measures of transit time of a set of spheres throughout the interior of a $10 \mathrm{~m}$-long pipe. Table 1 summarizes the results of this verification, showing the difference between the measured transit time and the expected transit time (Diff), and this error in per cent, for some values of water flows.

\begin{tabular}{|c|c|c|c|c|c|c|c|c|c|}
\hline & & & & & & $\begin{array}{r}\text { Flov } \\
1000 \\
\end{array}$ & & & \\
\hline Ball & Type & $\begin{array}{c}\text { Diameter } \\
(\mathrm{mm})\end{array}$ & $\begin{array}{l}\text { Density } \\
\left(\mathrm{g} / \mathrm{cm}^{3}\right)\end{array}$ & $\begin{array}{c}\text { Diff } \\
\text { (s) }\end{array}$ & Error & $\begin{array}{l}\text { Diff } \\
\text { (s) }\end{array}$ & Error & $\begin{array}{c}\text { Diff } \\
\text { (s) }\end{array}$ & Error \\
\hline 1 & Acrilic & 25 & 1,3 & 0,96 & $1,94 \%$ & 0,03 & $0,09 \%$ & 0,58 & $2,26 \%$ \\
\hline 2 & Acrilic & 25 & 1,3 & 1,05 & $2,11 \%$ & 0,05 & $0,16 \%$ & 0,77 & $2,97 \%$ \\
\hline 3 & Acrilic & 25 & 1 & $-0,44$ & $0,88 \%$ & 0,62 & $1,57 \%$ & 0,04 & $0,14 \%$ \\
\hline 4 & Acrilic & 25 & 1 & $-0,64$ & $1,27 \%$ & 0,24 & $0,76 \%$ & 0,11 & $0,38 \%$ \\
\hline 5 & Acrilic & 20 & 1 & $-0,55$ & $1,09 \%$ & 0,23 & $0,73 \%$ & 0,24 & $0,91 \%$ \\
\hline 6 & Acrilic & 20 & 1 & 0,34 & $0,67 \%$ & 0,36 & $1,13 \%$ & 0,07 & $0,29 \%$ \\
\hline 7 & Wood & 25 & 1 & $\begin{array}{l}-0,39 \\
\end{array}$ & $0,75 \%$ & 0,20 & $0,62 \%$ & 0,05 & $0,21 \%$ \\
\hline 8 & Wood & 25 & 1 & 0,70 & $1,35 \%$ & 0,11 & $0,34 \%$ & 0,04 & $0,17 \%$ \\
\hline 9 & Wood & 20 & 1 & 0,72 & $1,38 \%$ & 0,14 & $0,44 \%$ & 0,11 & $0,44 \%$ \\
\hline 10 & Wood & 20 & 1 & 1,08 & $2,07 \%$ & 0,13 & $0,39 \%$ & 0,06 & $0,18 \%$ \\
\hline & & Average & $\rho=1$ & 0,10 & $0,19 \%$ & 0,02 & $0,05 \%$ & 0,01 & $0,03 \%$ \\
\hline
\end{tabular}

Table 1. Travelling times along pipes for different sensors 
As this table shows, this is a technique with small error, and you can trust it to deduce the position. You can also make an individual adjustment to correct the position proportionally to the difference between the expected time and the transit time measured.

\subsection{System Architecture}

In order to achieve the spatial and temporal behavior of the fluid temperature along the $\mathrm{BHE}$, the instrument has been divided into three parts:

- A set of autonomous sensors

- A device for control, recording, and analysis

- A hydraulic system

In Figure 2, we present the logic diagram of the instrument; the hydraulic system comprises a water tank, a circulation pump, a flow meter, and two special valves for the insertion and extraction of the autonomous temperature probes. A laptop is the device that supports the control and human interface by a Windows program for TRT configuration, acquisition, and analysis of the values of measured temperature. Finally, a set of small balls $25 \mathrm{~mm}$ in diameter, contain the electronic circuitry of the autonomous temperature probes.

Also, a set of sensors monitors several variables during the running of TRT, such as the inlet and outlet water temperature of BHE, the temperature of the tank, as well as the pressure in the pipes.

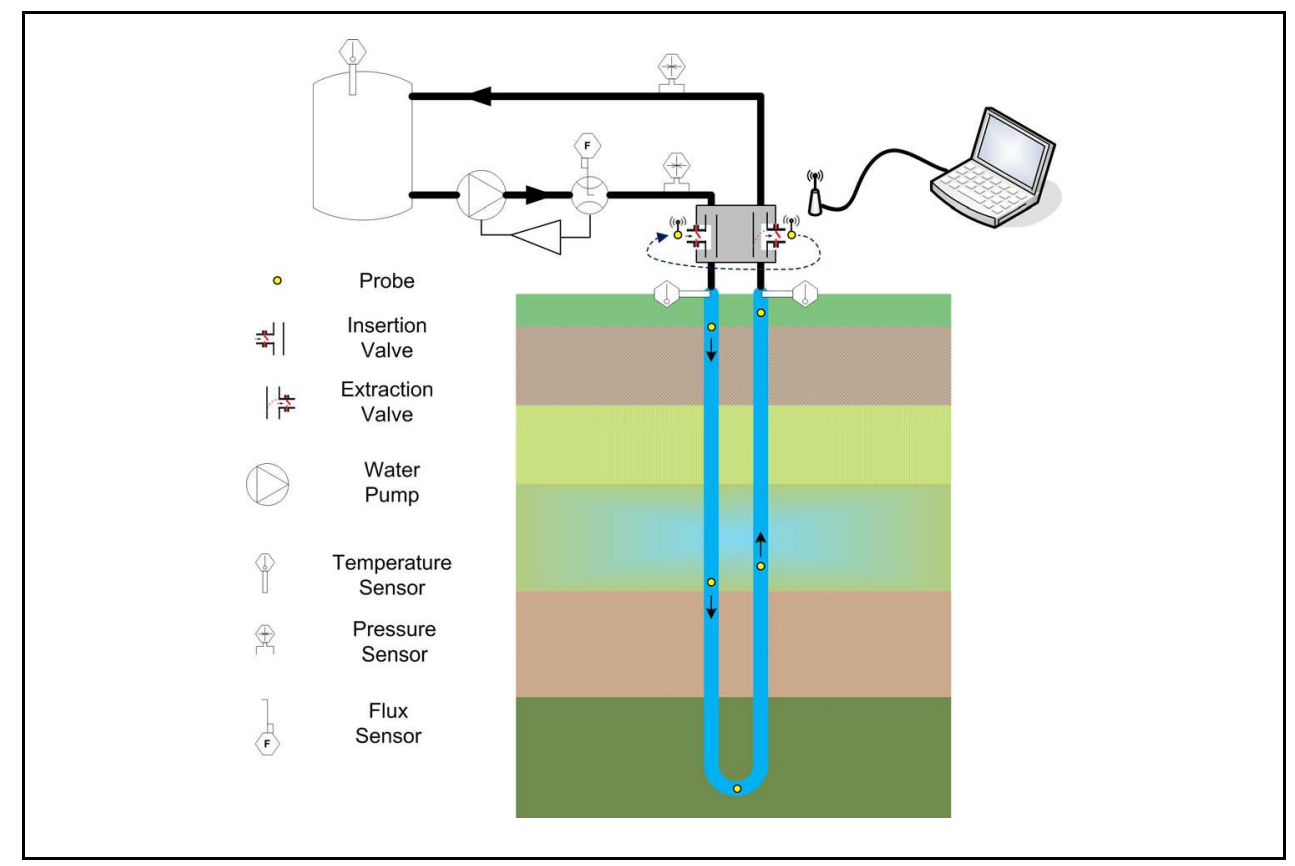

Fig. 2. Diagram of system architecture 
The hydraulic circuit comprises a water tank, as buffer for the thermal fluid, an electronically controlled circulation pump, a flow meter, and two valves, one for inserting probes and another for their extraction. The water temperature can be set through an electric heater that is controlled by the program that runs on the PC, which also controls the flow of water that is injected into the BHE pipe. The insertion of the probes is performed with selected time intervals in terms of realizing the TRT, controlled by the PC. When extracted, the probe is situated at the point of data discharge and, once it is completed, the data contained in the probe is deleted and, then, it is prepared for the next insertion.

A program for PC that controls the configuration, execution, and analysis of a TRT has been developed. The graphical user interface (GUI) has been done in Matlab GUI.

The program performs the following tasks:

- Setting TRT parameters: allows to be introduced the values for the test, water flow, spatial resolution, and time insertion.

- $\quad$ Setting of BHE parameters: allows the BHE characteristics to be introduced.

- Control of acquisitions: begins and ends TRT and shows the number of introduced and recovered probes.

- Control of hydraulics devices: adjust in closed loop the water flow and the temperature of tank, it also controls the probe insertion and extraction.

- Recording data: saves a file with the data to disk, in Excel format or csv format.

- Real time display: presents the monitored temperature of fluid in graphical form.

- Communications management: the PC assumes the role of wireless network coordinator.

The autonomous sensors are key components of the instrument. They are devices that measure the thermal evolution of an elementary volume of water along the BHE pipe. Its sizes must be as small as possible so they can move easily through the pipes carried by the water flow, and at the same time be able to contain an acquisition system, temporary storage, and unloading of temperature data. To achieve these functions and capabilities, a circuit has been designed based on the CC1010 transceiver that allows you to include it in a sphere with a diameter that is smaller than $25 \mathrm{~mm}$. A 4-layer PCBs has been designed to mount all the necessary components, (see Figure 3). The characteristics of each autonomous sensor are:

- Temperature range: $0-40{ }^{\circ} \mathrm{C}$

- Resolution temperature: $<0.05^{\circ} \mathrm{C}$

- Accuracy temperature: $<0.05^{\circ} \mathrm{C}$

- $\quad$ Rank sampling: 0.1-25 s

- $\quad$ Capacity sampling: 1000 samples

The mode of operation of the autonomous sensors is as follows:

- The control system selects an available probe and puts it in the status of test run

- It transfers the parameters of sampling

- It insert the probe into the BHE water flow

- The probe starts the process of acquiring, storing temperatures at fixed intervals

- After the tour, the temperature data are downloaded to the control system

- The probe goes into low-power mode 


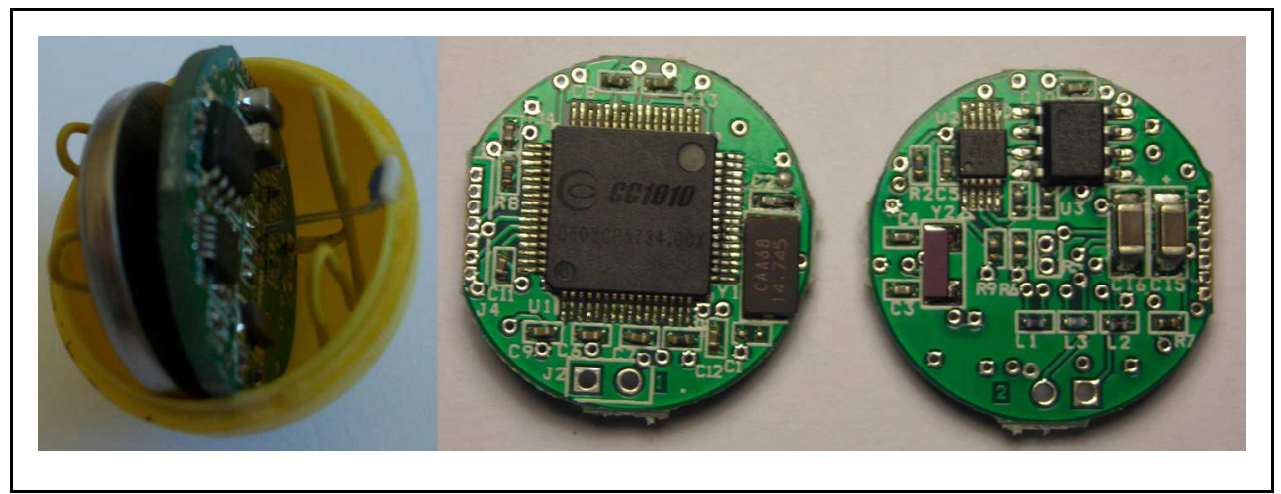

Fig. 3. Design and view of sensor

The final probe is enclosed in a sphere of $23 \mathrm{~mm}$ in diameter, which protects circuitry and allows the density of the probe to be equal to the water density.

The circuit for measuring the temperature has been designed based on a miniature Pt100 element that is located on the surface of the sphere. The conditioning circuit is designed to satisfy the size and consumption specifications. The Pt100 sensor is polarized by a current source that is integrated in an ultra low power consumption circuit and an instrumentation amplifier. This amplifier is also ultra low power, and the output signal is adjusted to the desired measurement range. Both components have a shut down signal that only switched on at the moment of measurement. The current consumption is $10 \mathrm{uA}$ in off mode and $1.58 \mathrm{~mA}$ in on mode.

\section{Firmware considerations}

The microcontroller containing each autonomous probe is responsible for the smooth running of the probe. It properly manages wireless communications, acquisition and storage of data, and the states of work of the circuit. To achieve the requirements of energy saving, the firmware developed for each of the autonomous probe has been structured in four states:

- Power down

- Configuration

- In acquisition

- Down load

The "Power down" state is the key to achieving that the probes have a long life. It is the state that stays in longer, and the state the probe enters at the end of each data collection cycle or if it exceeds a certain amount of time without communication with the control system. To escape the "Power down" state, a reset signal is applied to the microcontroller, which becomes active and enters to "Configuration" mode. This mode begins a communication with the coordinator node, where the probe is identified (ID) and receives the configuration of the monitoring and the actual clock. After a timeout, the sensor initiates the acquisition and the temporal buffering of temperatures, i.e., it switches to the "In acquisition" state. In 
this state, the microcontroller is sleeping between two acquisitions and is characterized by using the secondary oscillator, which only drives the peripheral that remains in operation: the timer that sets the sampling period. The circuit that conditions the signal from the Pt100 is activated moments before the measurement, and immediately returns to the low power state. At the conclusion of the scheduled number of acquisitions, the probe goes to the "Down load" state, recovering the main oscillator and establishing communication with the control system to transfer data. When the transfer is finished, it is passed to the "Power down" state.

The communications protocol is a simple design because it is during the wireless communications that thee consumption is higher Therefore, the fewer bits are transmitted more energy savings are achieved. All the messages that are exchanged between the transceivers are 6 bytes of data, a CRC-16, plus a header of 7 bytes for synchronization. The only exception is in the downloading of data, where the number of bytes transmitted is twice the number of acquisitions. The transfer rate is set at the highest rate possible, $76.8 \mathrm{kbs}$. The transmission power is also set at the minimum because the distance between transceivers is less than a meter, and the CC1010 can reach 100 meters at full power.

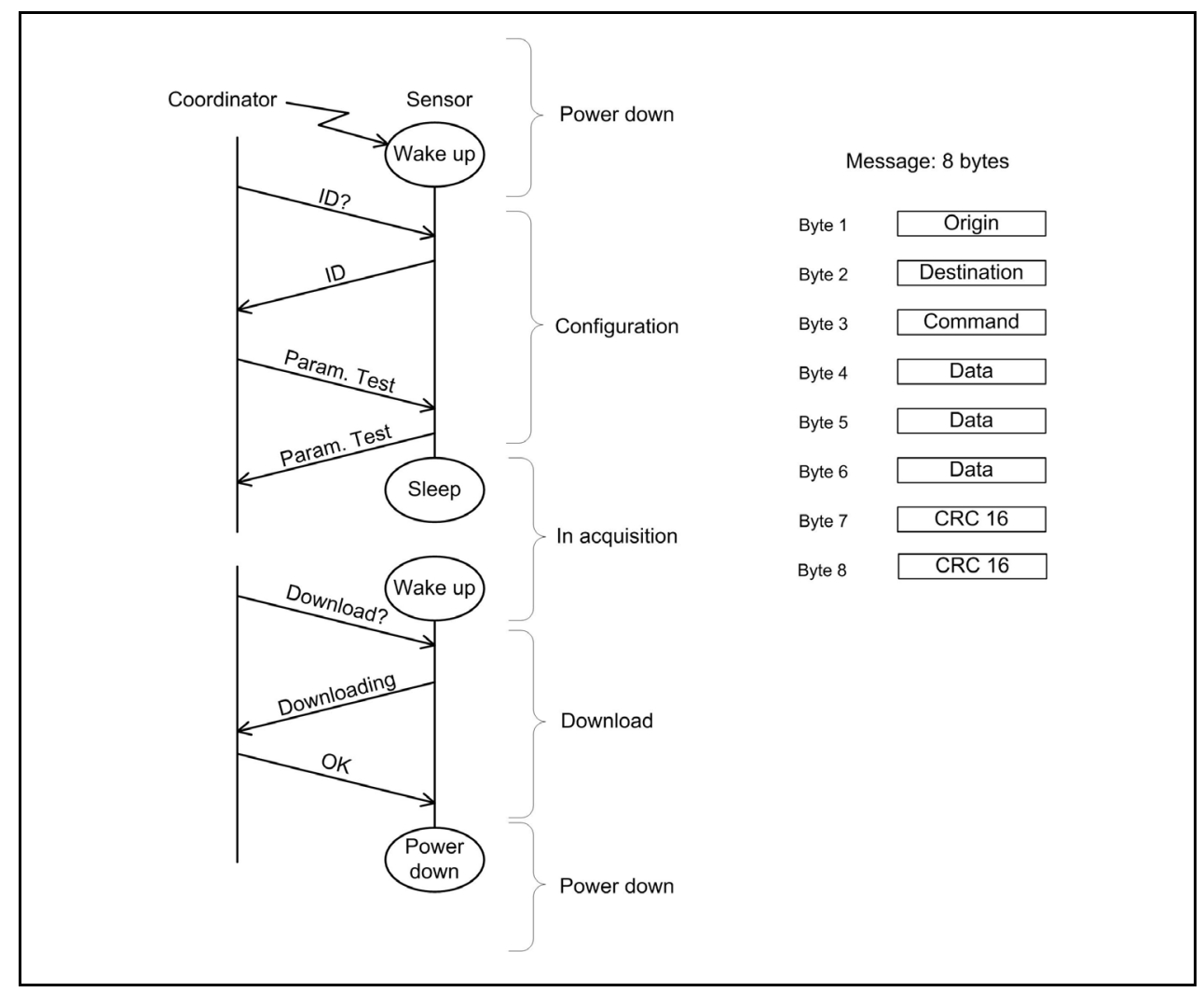

Fig. 4. Protocol communication 


\section{Time synchronization considerations}

Another key to the reliability of the obtained data is the time synchronization: all probes must have the same clock as a reference for the estimated time of acquisition. Since the evolution of temperature on the heat exchanger is slow, the accuracy in time between all the probes must be better than $100 \mathrm{~ms}$. There are different synchronization techniques in wireless sensor networks (Sundararaman 2005, Jones 2001), but to meet the energy restrictions of the instrument, the so-called Synchronization Reference Broadcasts (Elson 2002) was used for its ease of implementation and the low power consumption added.

The coordinator node is responsible for sending the reference clock to the probe, which has just been removed from the "Power Down" state, and requests its identification. Together with the command to start the acquisition, the current value of the clock is sent, and the probe will take this as its initial value of local clock. All subsequent acquisitions are referenced to this clock, thereby completing the synchronization. Although there will be a time delay between the clock sent by the coordinator and the sensor, due to the time of transmission and processing of messages (since all probes have the same latency) the time between two consecutive samples is well known. The confirmation of the correct initialization of the local clock of each sensor is done via the sensor's response message to the coordinator.

The frame of data downloaded from the sensor includes the clock that was posted at the beginning of the acquisition, which allows the synchronization of data with on accuracy of better than $100 \mathrm{~ms}$. Spatial synchronization is simpler; it depends of the moment in which the sensor is inserted into the flow of water, and this is controlled by the coordinator node, which performs the insertion of a certain time after receiving confirmation of the message startup acquisition. Since the flow rate and the section of the pipe are known, the point at which each temperature measurement is being made can be estimated perfectly.

\section{Other implementations}

The hardware solution adopted was taken after valuing other existing alternatives in the market that, still complying with the basic requirements, did not completely satisfy our needs. When we speak of RF communications, we have to always keep in mind the range, the charge, the need to use a standard, the price... In the current market, there are devices that work under the $\mathrm{GHz}$, devices that work above the $\mathrm{GHz}$, and devices that use a standard protocol (ZigBee, Wireless HART, Bluetooth...).

Our solution is from the first group due to the need to find an intermediate point among frequency of work, reach, power at the outset, environment, and consumption. Besides, we have an indispensable requirement, the size.

A success factor for the instrument is to obtain good quality communication while still maintaining very low consumption; the factors of propagation, attenuation, and shielding must be balanced to do this. Figure 5 shows the relationship between transmission quality and carrier frequency; the best choice is to work in the sub-Gigahertz range. 
Of the options under the $\mathrm{GHz}$ that use no standard protocol, the followings families of devices can be found:

- ADF70XX of Analog Devices

- MC33XXX of Freescale

- TDAXXXX of Infineon

- CC11XX of Texas Instruments

- rfPIC12XXXX of Microchip

- MAXXXX of Maxim

Table 2 summarizes the main characteristics of these families.

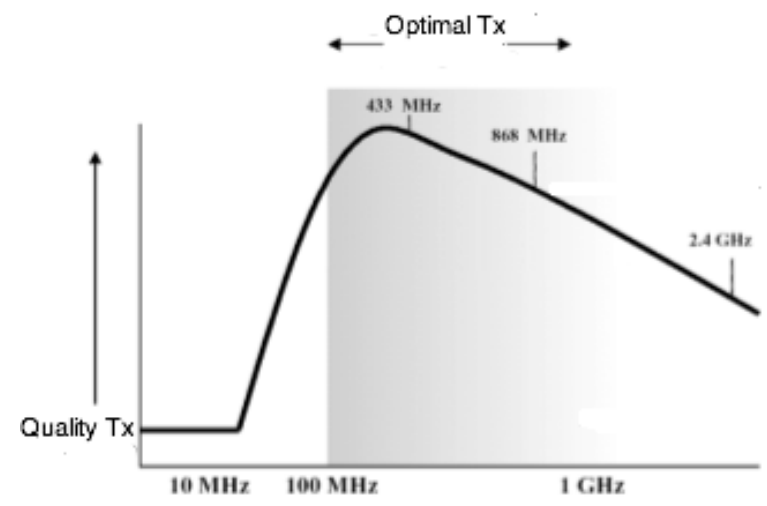

Fig. 5. Quality Tx versus frequency

\begin{tabular}{|c|c|c|c|c|c|c|c|}
\hline Device & $\begin{array}{c}\text { Band } \\
(\mathrm{MHz})\end{array}$ & Modulation & $\begin{array}{c}\text { Current } \\
(\mathrm{mA})\end{array}$ & $\begin{array}{c}\text { Voltag } \\
\mathrm{e}(\mathrm{V})\end{array}$ & $\begin{array}{c}\text { Baudrate } \\
(\mathrm{kbps})\end{array}$ & $\begin{array}{c}\text { Power } \\
(\mathrm{dBm})\end{array}$ & Package \\
\hline ADF70XX & $433-915$ & FSK/ASK & 30 & $2-3,6$ & $76 / 384$ & 13 & TSSOP \\
\hline MC33XXX & $304-915$ & OOK/FSK & 25 & $2,1-5,5$ & 20 & 7 & LQFP \\
\hline TDAXXXX & $434-870$ & ASK/FSK & 35 & $2,1-5,5$ & 100 & 13 & TSSOP \\
\hline CC11XX & $315-915$ & FSK/OOK & 16 & $2-3,6$ & 500 & 13 & QFN \\
\hline rfPIC12XXXX & $310-480$ & ASK/FSK & 20 & $2,7-5$ & 80 & 6 & SSOP \\
\hline MAXXXX & $300-450$ & ASK/FSK & 5,3 & $3,3-5$ & 70 & 10 & QFN \\
\hline
\end{tabular}

Table 2. Main characteristics for devices $<1 \mathrm{GHz}$

As can be observed, the Analog Devices solution complies with the broadcast velocity requirements, power, and package. However, it does not comply with the consumption nor does it incorporate the transmitter and the microcontroller in the same device. The same occurs with the families of Freescale, Infineon, and Maxim; although Maxim has the lowest consumption.

The families of Texas Instruments and of Microchip meet the requirement of having a single chip for both components, although the price was higher than that of the solution adopted. 
If we go to solutions above the $\mathrm{GHz}$ that do not require a standard, the following families can be found:

- MC13XXX of Freescale

- CC25XX of Texas Instruments

- CYWMXXXX of Cypress

- CyFi of Cypress

- MRF24JXX of Microchip

Table 3 summarizes the main characteristics of these families.

\begin{tabular}{|c|c|c|c|c|c|c|c|}
\hline Device & $\begin{array}{c}\text { Band } \\
(\mathrm{GHz})\end{array}$ & Modulation & $\begin{array}{c}\text { Current } \\
(\mathrm{mA})\end{array}$ & $\begin{array}{c}\text { Voltag } \\
\mathrm{e}(\mathrm{V})\end{array}$ & $\begin{array}{c}\text { Baudrate } \\
(\mathrm{kbps})\end{array}$ & $\begin{array}{c}\text { Power } \\
(\mathrm{dBm})\end{array}$ & Package \\
\hline MC13XXX & 2,4 & GFSK/MSK & 35 & $1,8-3,6$ & 250 & 4 & QFN \\
\hline CC25XX & 2,4 & GFSK/MSK & 23 & $2-3,6$ & 500 & 10 & QLP \\
\hline CYWMXXXX & 2,4 & GFSK & 20 & $2,7-3,6$ & 64 & 17 & QFN \\
\hline CyFi & 2,4 & GFSK & 12 & $1,8-3,6$ & 1000 & 12 & QFN \\
\hline MRF24JXX & 2,4 & GFSK/MSK & 22 & $2,3-3,6$ & 250 & 3 & QFN \\
\hline
\end{tabular}

Table 3. Main characteristics for devices $>1 \mathrm{GHz}$

The family of Freescale with these circuits for wireless communications, together with the microcontrollers of very low consumption of 8 bits of the family S08, allow ready point and point-to-multipoint communications to be implemented. This family is not of interest due to the high consumption and the need to have two components.

Texas Instruments acquired Chipcon to complete its range of wireless products including the Zigbee. Since the transceiver CC25XX has very few components, it does not need an electric antenna switch or a filter, providing great benefits and low consumption. It also offers programmable power sensibility at the outset. The CC25XX is a circuit of very low consumption that includes the transmitter and a microcontroller based on the core 8051 at $32 \mathrm{MHz}$.

Cypress began with RF solutions to $2,4 \mathrm{GHz}$ for PC and the USB markets. It has several characteristics that distinguish it from other competitors such as very low consumption, immunity to interferences, generation of $\mathrm{CRC}$, an auto transactions sequencer, etc. The advantages of this technology is that it has entered the consumer market (mice, keyboards, joysticks, ...) as well as the industrial market at a very low cost for ready point or point-tomultipoint applications. This technology can also be used even though the price is a lot higher than the solution adopted.

Cypress also presents a solution called CyFi to 2,4 GHz optimized for control since it has a PSoC microcontroller and a DSSS transmitter with, with a protocol that is easy to use for a network in star and with optimized consumption. The RF solution CyFi, of low consumption, is extremely dependable and easy to use to $2,4 \mathrm{GHz}$ within an extensive range of applications. It allows designers to create high reliability systems in wireless communication, reducing the complexity of development and ensuring low power consumption. The CyFi networks vary the channel of work dynamically, the velocity of broadcast and the real-time power at the outset in order to maintain dependable communications in the presence of interferences. Besides having very low activity and a 
sleep mode, the CyFi solution greatly improves low consumption. CyFi networks minimize periods of peak consumption and maximize the periods of low power state. This solution was not adopted due to the difficulty of integrating it into the size of our system when using two components.

Microchip offers a solution based on its microcontrollers and a proprietary protocol called Miwi $^{\mathrm{TM}}$ (Microchip Wireless). It is directed to low cost devices and networks that do not need high transfer of data, over short distances (100 meters without obstacles), and with minimum energy consumption. As occurs with $\mathrm{CyFi}$, the reduced space of our system forces us to reject this solution. We can conclude that within the market of wireless technologies, there is an extensive range of possibilities. Some of them may improve and change continuously, and we must keep them in mind for a new generation of instrument.

\section{Energy harvesting}

European legislation imposes restrictions on the use of batteries in electronic devices (European Parliament and Council, Directives 2006/66/EC and 2008/103/EC) and their recycling. The instrument developed uses button batteries to supply the autonomous probes; its final design must meet current legislation. While this directive covers exceptions to the restrictions on the use of batteries, one way of reducing their presence, without compromising the design, is to completely dispense with batteries or reduce the needs of replacing them by increasing the lifetime of the sensors. The most convenient way to achieve this is to use energy that can be collected in the environment, i.e., using techniques of "energy harvesting". Energy harvesting has become an important emerging area of low power technology (Cymbet 2009, Mateu 2007) that can provide energy for smaller-scale needs such as sensor networks, utilizing the vibrations inherent in structures, vehicles, and machinery or from wind and solar systems. These can drive sensors while eliminating the need for wires and batteries.

The energy sources that are most commonly used in energy harvesting are mechanical energy (vibration), light, electromagnetic, thermal and piezoelectric (Paradiso 2005). The power that can be captured from these sources is summarized in Table 4.

\begin{tabular}{|c|c|c|}
\hline Source & Power & Harvesting technologies \\
\hline Light & $\begin{array}{c}100 \mathrm{uW} / \mathrm{cm} 2 \text { to } \\
100 \mathrm{~mW} / \mathrm{cm} 2\end{array}$ & Photovoltaic \\
\hline Vibrational & $\begin{array}{c}4 \mathrm{uW} / \mathrm{cm} 3 \text { to } \\
800 \mathrm{uW} / \mathrm{cm} 3\end{array}$ & Piezoelectric cantilever \\
\hline Thermoelectric & $60 \mathrm{uW} / \mathrm{cm} 2$ & Thermogenerator \\
\hline Radio frequency & $\sim 1 \mathrm{uW} / \mathrm{cm} 2$ & Antenna \\
\hline Push button & $50 \mathrm{uJ} / \mathrm{N}$ & Electromagnetic, piezoelectric \\
\hline
\end{tabular}

Table 4. Capabilities of energy harvesting

In our instrument, we estimate that energy harvesting can be applied to power the sensors, using light or heat as an energy source or heat. With light, we can embed small photovoltaic cells in the cover of the sensor. With heat, we can incorporate small thermo generators based on Seebeck effect in the cover of the sensor. A circuit for power conversion and energy storage should be added. The device for storage can be a secondary battery or a capacitor 
(supercapacitor, Goldcap, etc.). The first method allows more energy density, but has limited life due to charge-discharge cycles and presents a small discharge current. The second method has an infinite life that is not affected by charge- discharge cycles, and presents a discharge curve that is non constant and has a small density of energy.

\section{Conclusions}

Achieving GCHP designs that are more accurate and tailored to soil conditions requires new tools and methods for calculating thermal soil properties. For the expansion of GCHP, it is essential to develop simpler and more economic methods in time and cost for BHE sizing. The instrument under development contributes to this goal by providing a device that offers easy transportation and installation, small size, and the possibility of operation by nonspecialists.

We have verified that it is possible to insert and extract small probes, which contain a miniaturized acquisition system, for temperature monitoring of the water flowing along the pipes of the BHE. It is possible to configure each probe with the desired parameters for monitoring temperature inside the pipes by wireless transmission. In autonomous mode, each probe completes the acquisition and, once the probe is extracted, downloads automatically the acquired data also by wireless transmission. The data collected and recorded on a PC, allows the design of a new analysis that takes into account the dynamics of the BHE. Some as yet untapped possibilities should be studied and quantified, such as groundwater flows, the effects of convective wet layers, etc. Accurate assessment of soil thermal recovery, and hence, the effects of saturation and thermal degradation of the efficiency that can occur in a particular installation must also be studied and quantified.

\section{Acknowledgments}

This work has been supported by the Spanish Government under projects "Modelado y simulación de sistemas energéticos complejos" (2005 Ramón y Cajal Program), "Modelado, simulación y validación experimental de la transferencia de calor en el entorno de la edificación" (ENE2008-0059/CON) and by the Valencian Government under project "Diseño y desarrollo de un instrumento de medida para la caracterización de intercambiadores de calor." (GV/2007/058).

The instrument has been patent pending since November of 2008.

\section{References}

Austin, W. A. (1998). Development of an in-situ system for measuring ground thermal properties. M.S. thesis, Oklahoma State University, Stillwater, OK, USA, 177 pp.

Beier, R.A. (2008). Equivalent Time for Interrupted Tests on Borehole Heat Exchangers. International Journal of HVAC \& R Research 14, 489-503.

Bose, J.E.; Smith, M.D.; Spitler, J.D. (2002). Advances in ground source heat pump systems. An international overview. $7^{\text {th }}$ IEA Conference on Heat Pump Technologies, Beijing (China)

Carslaw, H.S.; Jaeger, J.C. (1959). Conduction of Heat in Solids, Oxford University Press, New York, NY, USA, 510 pp. 
Cymbet Corporation (2009). White paper: Zero power wireless sensor http:/ / www.cymbet.com

Elson, J.; Girod, L.; Estrin, D. (2002). Fine-Grained network time synchronization using reference broadcasts. Proceedings Fifth Symposium on Operating Systems Design and Implementation (OSDI 2002) Vol. 36, 147-163.

Eskilson P. (1987). Thermal Analysis of Heat Extraction Boreholes. PhD. Thesis, Dept. of Mathematical Physics, University of Lund, Lund, Sweden, 264 pp.

Eklöf, F.; Gehlin, S. (1996). A mobile equipment for Geothermal Response Test. M.S. thesis, Lulea University of Technology, Lulea, Sweden, $65 \mathrm{pp}$.

European Parliament and Council, Directive 2008/103/EC, Batteries and accumulators and waste batteries and accumulators as regards placing batteries and accumulators on the market

European Parliament and Council, Directive 2006/66/EC, Batteries and accumulators and waste batteries and accumulators and repealing Directive

Genchi, Y.; Kikegawa, Y.; Inaba, A. (2002) CO2 payback-time assessment of a regional-scale heating and cooling system using a ground source heat-pump in a high energyconsumption area in Tokyo. Applied Energy Vol.71, 147-160

Hellström, G. (1991). Thermal Analysis of Duct Storage System. Dep. of Mathematical Physics, University of Lund, Lund, Sweden, $262 \mathrm{pp}$.

Hurtig, E.; Ache, B.; Großwig, S.; Hänsel, K. (2000). Fiber optic temperature measurements: a new approach to determine the dynamic behavior of the heat exchanging medium inside a borehole heat exchange. TERRASTOCK 2000, 8th International Conference on Thermal Energy Storage Stuttgart. August 28th to September 1st, 2000.

Jones, C.E.; Sivalingam, K.M.; Agrawal, P.; Chen, J. (2001). A survey of energy efficient network protocols for wireless networks. Wireless networks 7, 343-358

Lund, J.W. (2000). Ground source (geothermal) heat pumps. In: Course on heating with geothermal energy: conventional and new schemes. Lineau P.J. (editor). World Geothermal Congress 2000 Short Courses. Kazuno, Japan, pp. 209-236.

Martos, J.; Torres, J.; Soret, J.; Montero, A. (2008). Wireless sensor network for measuring thermal properties of borehole heat exchangers. Proceedings IEEE International Conference on Sustainable Energy Technologies (ICSET 2008), Singapur

Mateu, L.; Codrea, C.; Lucas, N.; Pollack, M.; Spies, P. (2007). Human body energy harvesting thermogenerator for sensing applications. International Conference on Sensor Technologies and Applications SENSORCOMM 2007,Valencia, Spain

Mogensen, P. (1983). Fluid to duct wall heat transfer in duct system heat storage. Proceedings of the International Conference on Surface Heat Storage in Theory and Practice, Sweden, Stockholm, pp. 652-657.

Nordell, B.; Reuss, M.; G. Hellström, G. (2006). Annex 21: Thermal Response Test. Draft.

Omer, A M. (2008). Ground-source heat pump systems and applications. Renewable and Sustainable Energy Reviews 12, 344-371.

Paradiso, J.A.; Starner, T. (2005). Energy scavenging for mobile and wireless electronics. IEEE Pervasive Computing Vol 4, Issue 1, 18-27

Rohner, E.; Rybach, L.; Schaärli, U. (2005). A new, small, wireless instrument to determine ground thermal conductivity In-Situ for borehole heat exchange design. Proceedings World Geothermal Congress 2005, Antalya, Turkey.

Sanner, B.; Karytsas, C.; Mendrinos, D.; Rybach, L. (2003). Current status of ground source heat pumps and underground thermal storage in Europe. Geothermics 32, 579-588. 
Spitler, J.D. (2005). Ground-Source heat Pump System Research - Past, Present and Future. International Journal of HVAC \& R Research 11, 165-167.

Sundararaman, B.; Buy, U.; Kshemkalyani, A.D. (2005). Clock synchronization for wireless sensor networks: a survey, Ad-Hoc network, 3(3): 282-323

Urchueguía, J.F.; Zacarés, M.; Corberán, J.M.; Montero, Á.; Martos, J.; Witte, H. (2008). Comparison between the energy performance of a ground-coupled water to water heat pump system and an air to water heat pump system for heating and cooling in typical conditions of the European Mediterranean Coast. Energy Conversion and Management 49, 2917-2923.

U.S. EPA, (2008). Energy Star Program, US Environmental Protection Agency. http://www.energystar.gov.

Witte, H.J.L.; van Gelder, G.J.; Spitler, J.D. (2002). In Situ measurement of ground thermal conductivity: a Dutch perspective. ASHRAE Transactions 108, 1-10. 


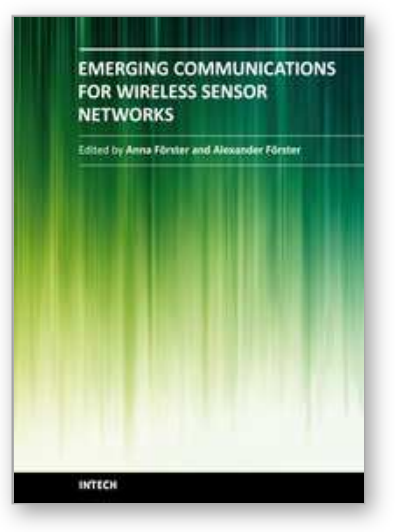

\author{
Emerging Communications for Wireless Sensor Networks \\ Edited by
}

ISBN 978-953-307-082-7

Hard cover, 270 pages

Publisher InTech

Published online 07, February, 2011

Published in print edition February, 2011

Wireless sensor networks are deployed in a rapidly increasing number of arenas, with uses ranging from healthcare monitoring to industrial and environmental safety, as well as new ubiquitous computing devices that are becoming ever more pervasive in our interconnected society. This book presents a range of exciting developments in software communication technologies including some novel applications, such as in high altitude systems, ground heat exchangers and body sensor networks. Authors from leading institutions on four continents present their latest findings in the spirit of exchanging information and stimulating discussion in the WSN community worldwide.

\title{
How to reference
}

In order to correctly reference this scholarly work, feel free to copy and paste the following:

Julio Martos, Alvaro Montero, Jose Torres and Jesus Soret (2011). Wireless Sensor Network for Monitoring Thermal Evolution of the Fluid Traveling inside Ground Heat Exchangers, Emerging Communications for Wireless Sensor Networks, (Ed.), ISBN: 978-953-307-082-7, InTech, Available from:

http://www.intechopen.com/books/emerging-communications-for-wireless-sensor-networks/wireless-sensornetwork-for-monitoring-thermal-evolution-of-the-fluid-traveling-inside-ground-heat-e

\section{INTECH}

open science | open minds

\author{
InTech Europe \\ University Campus STeP Ri \\ Slavka Krautzeka 83/A \\ 51000 Rijeka, Croatia \\ Phone: +385 (51) 770447 \\ Fax: +385 (51) 686166 \\ www.intechopen.com
}

\author{
InTech China \\ Unit 405, Office Block, Hotel Equatorial Shanghai \\ No.65, Yan An Road (West), Shanghai, 200040, China \\ 中国上海市延安西路65号上海国际贵都大饭店办公楼 405 单元 \\ Phone: +86-21-62489820 \\ Fax: +86-21-62489821
}


(C) 2011 The Author(s). Licensee IntechOpen. This chapter is distributed under the terms of the Creative Commons Attribution-NonCommercialShareAlike-3.0 License, which permits use, distribution and reproduction for non-commercial purposes, provided the original is properly cited and derivative works building on this content are distributed under the same license. 